\title{
Fatigue Behavior of Kevlar Composite with Graphene Filled Epoxy Resin
}

\author{
Vijaya Dharshan GN ${ }^{1}$, Akshay A ${ }^{2}$, Dr. Dalbir Singh Lohchab ${ }^{3}$, Dr. Ganesan $C^{4}$ \\ School of Aeronautical Sciences, Hindustan Institute of Technology and Science, \\ Rajiv Gandhi Salai (OMR), Padur,Chennai - 603 103, Tamilnadu, India.
}

\begin{abstract}
This study is aimed to investigate the fatigue behavior of the Kevlar composites reinforced epoxy infused with Graphene nanoparticles. Most of the engineering components used in defense, aerospace, biomedical, automobile industries, military appliances, and in high mechanization like Formula One Racing car, uses aramid fiber as the main component in their structural design due to them being heated resistive, strong high-performance fibers. However, Kevlar has low compressive strength and other cons thereby limiting its mechanical and electrical behavior. In this study, kevlar-49 and graphene nanoparticle-infused epoxy are sandwiched together using the technique of vacuum resin infusion. Graphene, Graphite, Carbon Nanotube, etc., the visual appearance is indifferent, and often leads to the misconception, hence Raman Spectroscopy was comprehensively done as it's an efficient method to prove the above-stated Nanoparticle in a nondestructive format. The fatigue test was conducted at a constant stress amplitude with a frequency of $10 \mathrm{~Hz}$, in accordance with ASTM D3479. The fatigue limit was read at a million cycles (1005498 cycles). The visual view of the fatigue experiment has shown the damage propagation of these developed composites which is started by matrix cracking and followed by fiber breakage and delamination between Kevlar fiber layers once the developed composite reaches the failure point. Thus, this development of Nanoparticle reinforced composite shows good agreement findings and has high potential to replace or reduce the usage of general synthetics fiber.
\end{abstract}

Keywords: Graphene; Kevlar; Kevlar composite; Raman Spectroscopy; Fatigue.

\section{INTRODUCTION}

Graphene has been an age long material that researchers have been keenly interested in. Graphene is known to have excellent mechanical and electrical behaviour. And it is a very light weight material, thereby opening windows of usage in the aircraft industry and Automotive industry as well as many other industries. Kevlar on the other hand is an aramid fiber, whose usage is widespread across many fields due to its incredible mechanical properties. It is a heat resistive strong synthetic fiber material and has high tensile strength. Its widely known for its usage in the bulletproof vests and body amours, but also has dozens of other applications as well. Its tightly woven fibers make it an excellent antiballistic material and requires a great deal of energy to penetrate through. But if we want the material to withstand high velocity impact of high loads, the material has to be made thicker adding more layers to increase its tensile strength. And the material must also have a extended usage life and should have improved wear and tear resistance In our experimental project, we have fabricated Kevlar composites with 5 different graphene nanoparticle concentration reinforced epoxy resin. The concentration ranging from $0 \%$ to $1.75 \%$ of the nanoparticles. The raman spectroscopy test is done as it's a effective nondestructive testing method to identify and verify the nanoparticle to be graphene. The tensile test in done using the MTS Landmark testing machine, to collect data on the max Tensile load that the specimen can withstand before failure and also the elongation. This data is used to find the ultimate tensile strength of each specimen of five different concentration of graphene- Kevlar composite. The fatigue test is carried out using the MTS Landmark 100kN Fatigue testing machine. The data acquired from the tensile test is analyzed and stress ration and frequency for the fatigue test is determined. Then the specimens are subject to Fatigue test, from which the number of fatigue cycles to failure for each material is determined. These fatigue cycles for each specimen tell us about the fatigue life, Max tensile load the material can withstand and the level of wear and tear the each of the five different concentrations of graphene - Kevlar composite can withstand before failure.

\section{MATERIALS AND METHODS}

Aramid Fibers provide the highest tensile strength-to-weight ratio and are featherlight among reinforcing fibers and it has negative axial coefficient of thermal expansion, which means laminates made with kevlar can be made thermally stable in all dimensions and it is impervious to effect and abrasion. The advantages discussed above helped us to select Kevlar-49 as our Fiber. .A.R. BUNSELL has stated that Polyacrylonitrile fibres have been found to fail during cycling after splitting of the structure. These splits do not appear necessarily to originate at the fibre surface and there is often more than one split in the same region so giving rise to fairly complex fracture morphologies, hence We have chosen 200 GSM. Kevlar-49 Fiber It is woven roving, bi-directional fiber. which provides better result and good mechanical strength as guided by our experienced industry people and by referring other research papers. It is woven roving, bi-directional fiber. Graphene as Nano filler is chosen for the study as graphene is having unilateral of carbon atoms arranged in a hexagonal lattice. Graphene is a kind of metal that has an element of covering between the conduction groups and the valence. These are kept in a structure of lattice hexagonal that has a solitary layer of carbon atoms. It is the thinnest material ever discovered until now and as well as it is very much strong enough in its working. its layer has only a single one of atoms of carbon that is mostly pliable in nature. Epoxy resin LY556 is chosen for this project as it was economical, easily available and displayed all the 
properties we were looking in a resin. The following abilities helped us to narrow our choice, Better adhesive properties, Superior mechanical properties, Improved protection to fatigue and micro cracking, Reduced corruption from water entrance, Increased protection to osmosis and low viscosity system.Aradur HY951 is a Low viscosity, unfilled epoxy casting resin system, curing at room temperature. Its properties are Good resistance to atmospheric to atmospheric and chemical degradation. hardener is utilized despite the fact that they can apply to very specific sorts of materials having especially various qualities and capacities. The motivation behind having accelerators speeding up epoxy frameworks for explicit applications or restoring conditions in by and large various conditions. It speeds up the solidifying time. TETA(Triethylenetetramine).

This strategy is an augmentation of the wet lay-up and hand layup measure in that the pressing factor is applied to the cover once laid-up to improve its solidification. This is finished via fixing an adaptable plastic film or an elastomeric layer (silicon, nylon, or polyimide) generally called as "vacuum pouch" over the wet laid-up cover and onto the paraphernalia. The air under the sack is extricated by a vacuum siphon and in this way up to one air of pressing factor can be applied to the overlay to merge it, while guaranteeing expulsion of air pockets to greatest degree. In this manner, the vacuum pouch method is an improvement over the contact shaping cycle in that; it furnishes a close to void free composite with more prominent power over the thickness and fiber part of the formed item. Further, in the vacuum sack shaping procedure, a few handlings help like a permeable strip employ, a punctured plastic film or the release film and a non-woven texture breather (puffy fabric cloth) are put between the vacuum pack and the wet layup to work with expulsion of overabundance pitch from back to front affected by a consistently appropriated vacuum.

The Kevlar 49 fiber, Epoxy resin LY556 and hardener HY951 were supplied by hayael aerospace pvt ltd. Chennai

And graphene was supplied by adnano technologies, shimoga, Karnataka.

The fiber is cut as per our required size of the panel, the mold is first cleaned is isopropyl alcohol or acetone peel ply is used as the first layer in order to avoid excess resin on the mold and ensures smoothness of texture and 12 layers of Kevlar are stacked and the mixture of resin and hardener are spread over the layer of Kevlar and is followed for every succeeding layer, the resin and hardener are mixed in the ratio 10:1 with respect to the weight of the fiber i.e weight of fiber is $250 \mathrm{~g}$ then weight of resin LY556 is $250 \mathrm{gm}$ and weight of hardener is $25 \mathrm{gm}$. Graphene is mixed with the resin through the sonication process, where the weight of graphene is also considered with accordance to the weight of fiber. The graphene concentrations considered for this project are, $0.25 \%, 0.75 \%, 1.25 \%$ and $1.75 \%$.

The weight of nano filler that was utilized for this project are $0.625 \mathrm{~g}, 1.875 \mathrm{~g}, 3125 \mathrm{~g}, 4.37 \mathrm{~g}$ respectively. Once the stacking for the 12 layers are completed, on the top most layer permeable strip release film and breather a puffy fabric are kept in order to remove the excess resin from the composite. The setup is put into a vacuum pack for curing of the composite, where at $1 \mathrm{~atm}$.
Pressure under room temperature the excess resin is pulled out from the composite hence, it minimizes the voids and gaps in the composite. and makes the composite more stable and gives a good finish to the panel.

Waterjet cutting was preferred to cut the specimens out of the sample, waterjet cutting was preferred because Kevlar being a waterproof material and could be delaminated during the machine cutting process hence waterjet cutting was preferred as it has more precision and does not let the panel de laminate.

\section{RESULTS AND DISCUSSION}

\section{Raman Spectroscopy}

Raman spectroscopy is a generally utilized spectroscopic technique. Exceptionally explicit spectra of materials can be gotten which can measure up and recognized by utilizing otherworldly data sets. Like IR spectroscopy, basic vibrations of particles are analyzed which is significant for a total comprehension of compound responses. A Raman range includes various pinnacles, showing the power and frequency position of the Raman dissipated light. Each pinnacle relates to a particular sub-atomic bond vibration, including singular bonds, for example, C-C, C=C, N-O, C-H and so forth, and gatherings of bonds, for example, benzene ring breathing mode, polymer chain vibrations, grid modes, and so on Both Raman and FTIR spectroscopy give a range normal for the particular vibrations of an atom ("sub-atomic finger impression') and are significant for distinguishing a substance.

Graphene is basically a nano particle about an atom thick but kept as a cluster it is visible to naked eyes and appears to be some sort of black powder. Graphene, Graphene oxide, Carbon nano tubes, Graphite etc, carbon related materials in physical visualization resemble each other and there is no effective method to identify Graphene from the other related material by visual inspection without performing chemical or destructive tests. Graphene being a very expensive material, poses a difficulty even to waste 1 gram of the nano particle to perform chemical test as once the test is performed the material cannot be further used and a new sample of the material has to be manufactured.

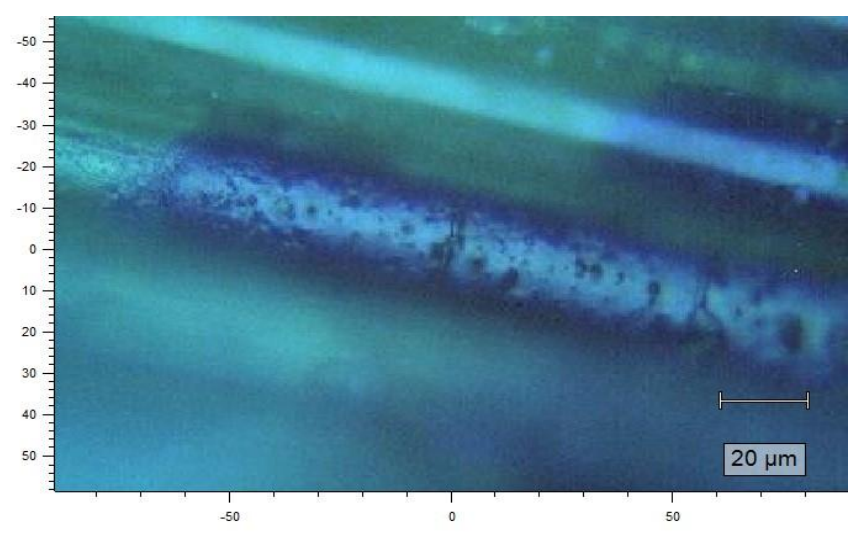

Fig. 3.1 Interlocking of Graphene over Kevlar fiber 
Hence Raman Spectroscopy emerged as the most effective nondestructive method to test the originality of the nano particle as graphene. Raman spectroscopy (and Raman imaging) has become a powerful, non-invasive method to characterize graphene and related materials. A large amount of information such as disorder, edge and grain boundaries, thickness, doping, strain, and thermal conductivity of graphene can be learned from the Raman spectrum and its behaviour under varying physical conditions.

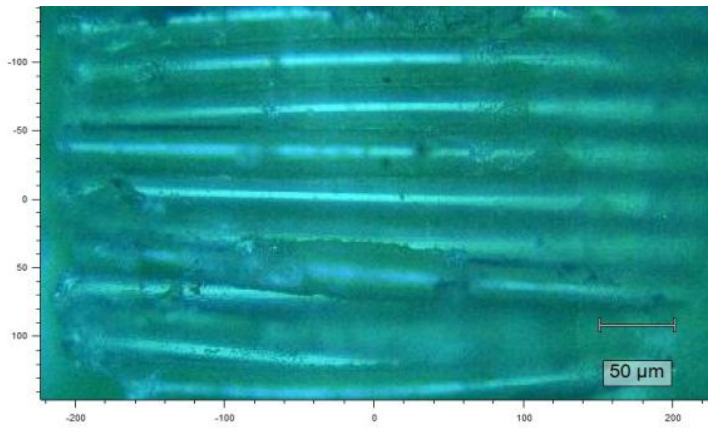

Fig.3.2 Raman Microscopy at 50 micrometer of $0 \%$ Graphene Kevlar Composite

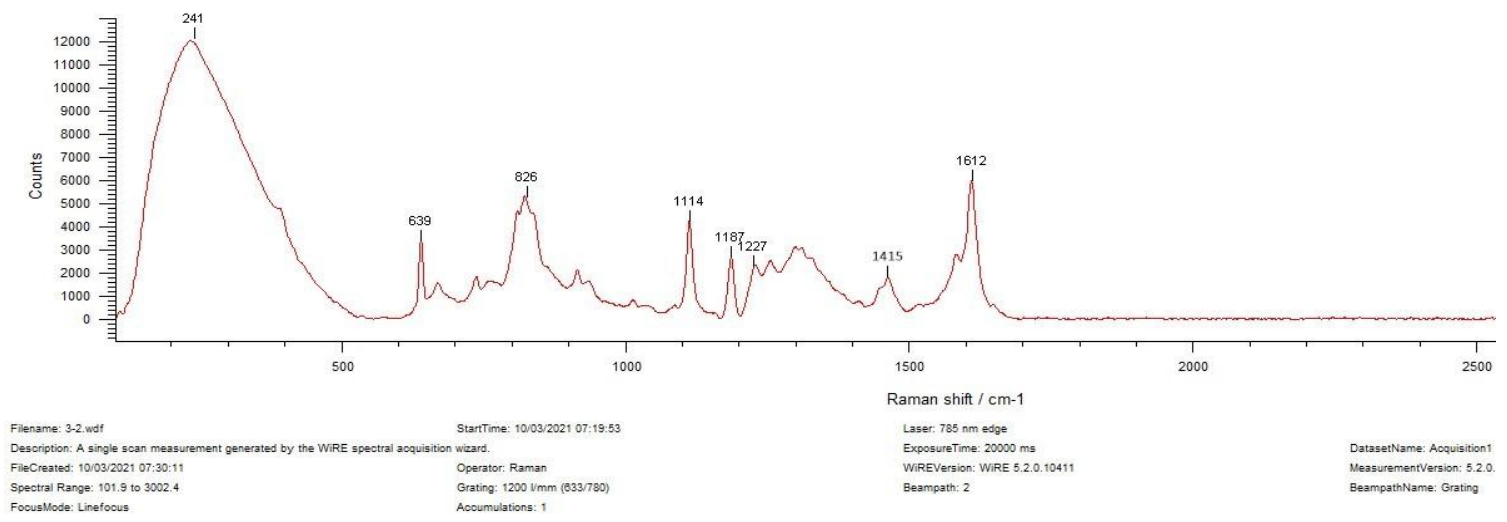

Fig. 3.3 Raman Spectroscopy graph of 0\% Graphene Kevlar Composite

Raman Microscopy of 0\% Graphene Kevlar Composite is shown in Fig. 3.2 at 200 micrometres and 50 micrometres. The microscopy image shows us the Kevlar fibre weaving at $0^{0}, 90^{0}$ orientation. We can also see that the sample is plain Kevlar fibre without any nano particles or fillers.

The Spectroscopy graph of $0 \%$ Graphene Kevlar composite is shown in Fig. 3.3. The graph contains Raman peeks such as 1612 that indicates that the tested sample is Kevlar. The peek obtained by this graph were compared and correlated with research papers and existing data to identify the Raman peek for Kevlar. The other small peeks in the above graph are of minor impurities, dirt and of the chemical bonding atoms.

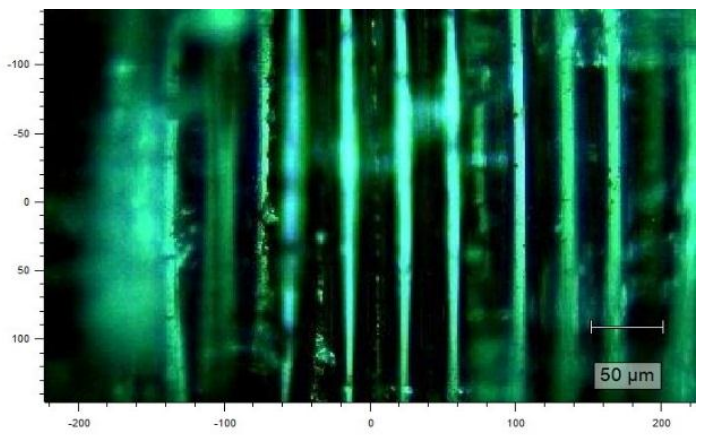

Fig. 3.4 Raman Microscopy at 50 micro meter of $1.75 \%$ Graphene Kevlar Composite

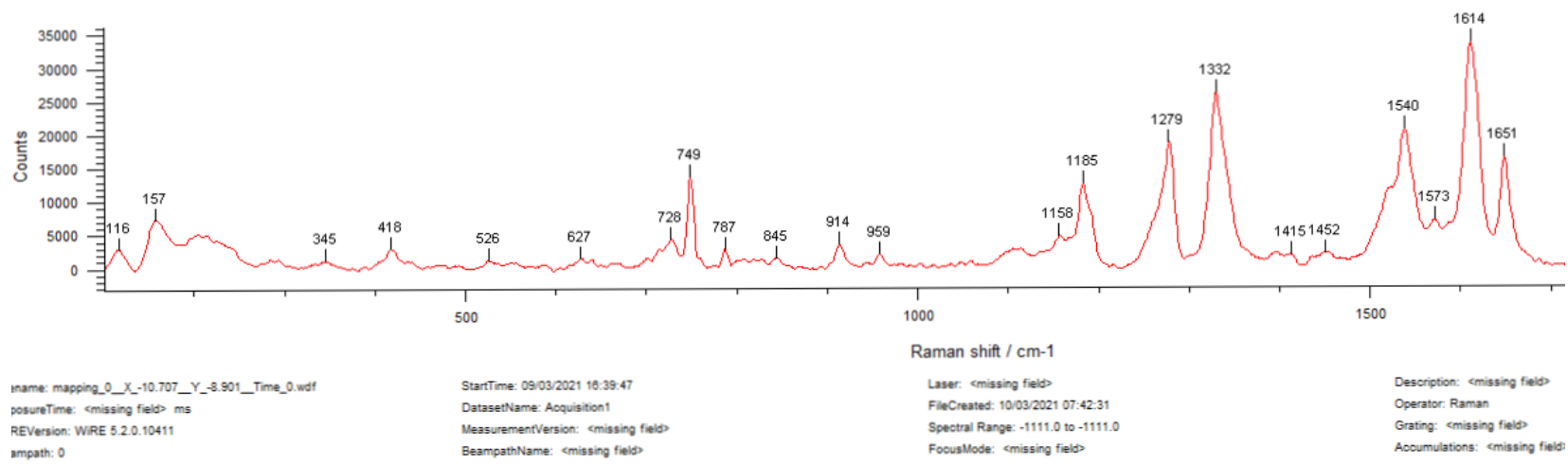

Fig.3.5 Raman Spectroscopy Graph of 1.75\% Graphene Kevlar Composite 
The Raman Microscopy images of Kevlar composite with $1.75 \%$ Graphene reinforced epoxy resin at 200 micrometres and 50 micrometres is shown in Fig.3.4. In comparison with $1.25 \%$ Graphene compositions these images show that Graphene distribution has significantly improved, and the accumulation is more and approximately even over the surface of Kevlar. The Gaps (arears where there is no graphene) are reducing substantially in the surface of Kevlar. There is definite bonding between the Graphene nanoparticles and Kevlar fibres.

The Raman Spectroscopy graph of $1.75 \%$ Graphene Kevlar composite is given in Fig.3.5The Graphs shows significant peeks of Graphene for nearly 30000 counts.
The below Fig. 3.6 show the Raman Spectroscopy mapping graph of the 5 different Graphene compositions reinforced Kevlar Composite samples. The Graphene Raman peeks, and the Raman peeks of Kevlar are clearly displayed on the graph, this shows and verifies that the nanoparticles present is all the different composite samples are indeed Graphene nanoparticles. The Raman peeks are often close calls from the standard Raman peeks values of the materials, this was later researched and identified to be due to the nano material being $99 \%$ pure. The drop in purity of the nanomaterial along with other subsidiary criteria is the reason for the Raman peeks to deviate slightly.

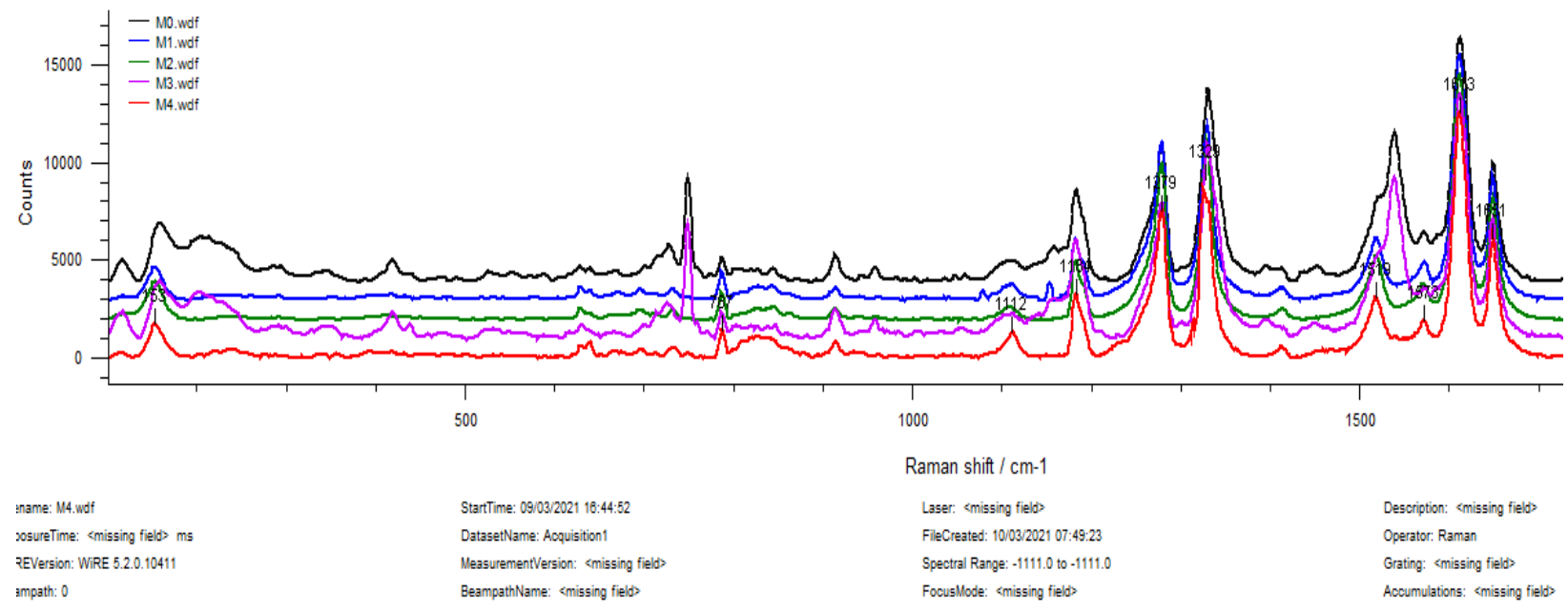

Fig. 3.6 Raman Spectroscopy Mapping of All the different compositions of Graphene

The below Fig. 3.7 shows the deposition/interlocking of Graphene with Kevlar fibres at 20 micrometres zoom. The area with Graphene accumulation and area without the nano particles are mapped and a gradient scale is depicted for the understanding of density of Graphene accumulation on the Kevlar fibres.

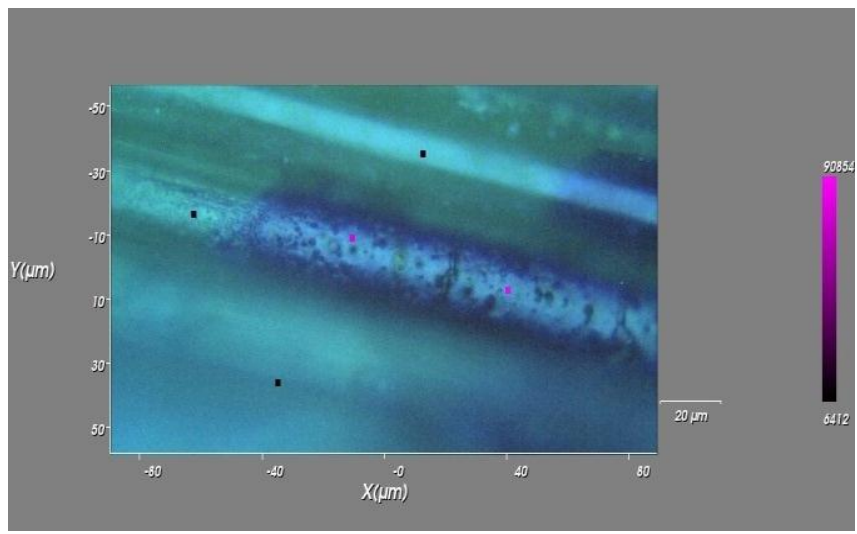

Fig. 3.7 Raman Microscopy of Graphene accumulation on Kevlar fibre

The main aim of this test was to identify the presence of Graphene Nanoparticles and verify its presence in the fabricated composites. The cluster of data we have received and present above provides proof that our chosen nanoparticle in the different composition Composite panels is Graphene and confirms that the interlocking and Co-bonding of the nanoparticles with the Kevlar fibres.

\section{Tensile Test}

The tensile test was conducted on the composite laminates fabricated for various concentrations of graphene are tested as per ASTM D 3039 standard using the MTC Landmark 100kN Testing machine. The tensile load is applied in gradual increasing manner on the laminates till the specimens are fractured. The tensile load is recorded as a function of increasing gauge length and is plotted in Fig. 6.14 and Fig. 6.16 for two different sample sets of five specimens.

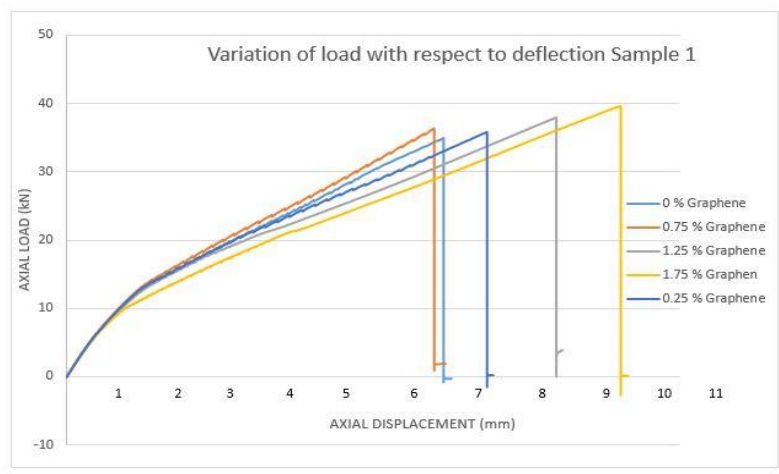

Fig. 3.8 Variation of load with respect to deflection 
The peak load of two sets of five different graphene concentrations specimens are tabulated in table 3.1.

Table 3.1 Max load of five different graphene concentrations specimen

\begin{tabular}{|c|c|c|c|}
\hline Specimen & $\begin{array}{c}\text { Sample 1 } \\
\text { Max load } \\
(\mathrm{kN})\end{array}$ & $\begin{array}{c}\text { Sample 2 } \\
\text { Max load } \\
(\mathrm{kN})\end{array}$ & $\begin{array}{c}\text { Average } \\
\text { Max load } \\
(\mathrm{kN})\end{array}$ \\
\hline $0 \%$ Graphene & 34.941 & 35.285 & 35.113 \\
\hline $0.25 \%$ Graphene & 36.342 & 36.685 & 36.5135 \\
\hline $0.75 \%$ Graphene & 37.973 & 38.895 & 38.434 \\
\hline $1.25 \%$ Graphene & 39.599 & 39.076 & 39.3375 \\
\hline $1.75 \%$ Graphene & 40.763 & 40.833 & 40.798 \\
\hline
\end{tabular}

It is evident that the Max load that the material can withstand before failure, increases with the addition/increase of Graphene percentage in the Kevlar composites.

Table 3.2 The ultimate tensile strength of two sets of five different graphene concentrations specimens

\begin{tabular}{|c|c|c|c|c|}
\hline \multirow{2}{*}{ Specimen } & \multirow{2}{*}{$\begin{array}{c}\text { Thickness } \\
(\mathrm{mm})\end{array}$} & \multicolumn{3}{|c|}{$\begin{array}{r}\text { Ultimate Tensile Strength } \\
\left(\mathrm{kN} / \mathrm{mm}^{\wedge} 2\right)\end{array}$} \\
\cline { 3 - 5 } & & Sample 1 & Sample 2 & Average \\
\hline $0 \%$ Graphene & 3 & 465.88 & 470.4667 & 468.173 \\
\hline $0.25 \%$ Graphene & 3 & 484.56 & 489.1333 & 486.846 \\
\hline $0.75 \%$ Graphene & 3.08 & 493.1558 & 505.1299 & 499.142 \\
\hline $1.25 \%$ Graphene & 3.15 & 502.8444 & 496.2032 & 499.523 \\
\hline $1.75 \%$ Graphene & 3.2 & 509.5375 & 510.4125 & 509.975 \\
\hline
\end{tabular}

The Ultimate Tensile Strength for two sets of samples of five different concentration of Graphene was calculation with respective Max load and cross-sectional area, and tabulation above in Table 3.2. The average Ultimate tensile strength of above the samples were also calculated and tabulated.

The Ultimate tensile values with respect to the Graphene concentration for both the sample sets are depicted in a comparative column graph in Fig. 3.9.

From the above figures and tables, we found that the tensile load is higher for $1.75 \%$ of graphene when compared to other concentration. There were significant improvements in the Max load that the specimen was able to withstand before failure, with the increase in Graphene concentration in the Kevlar composite panels. It was also found that for certain samples there was a rapid variation in tensile load due to uneven distribution and improper break down of graphene nano particles in resin. This occurs because of improper mixing of graphene with resin due to its viscosity. Further understanding of the failure can be obtained by doing Failure analysis of the broken specimen by undergoing SEM analysis and comparing with proper specimens.

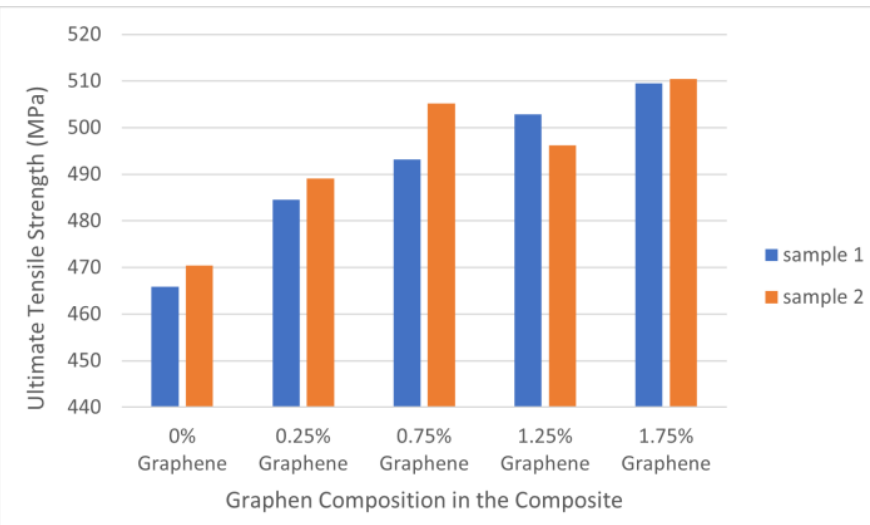

Fig. 3.9 Comparison Graph of Ultimate Tensile Strength variation of sample 1 and 2

\section{Fatigue Test}

The Fatigue test was conducted on the composite laminates fabricated for various concentrations of graphene are tested as per ASTM D D3479 standard using the MTC Landmark 100kN Testing machine. The tests were loaded cyclically at $60 \%, 70 \%$ and $80 \%$ of the respective panel Ultimate Tensile strength. Cyclic loads do increase gradually on the laminates till the specimens are fractured. The number of fatigue cycles are recorded as a function of Percentage of Ultimate tensile strength, Axial load, and Axial Displacement with a stress ratio of 0.3 for three sample sets of five different specimens.

Table 3.3 The average Number of Cycles of three sets of samples of five different graphene concentrations specimens.

\begin{tabular}{|c|c|c|c|}
\hline \multirow{2}{*}{$\begin{array}{c}\text { Specimen } \\
\text { (\% of Graphene in } \\
\begin{array}{c}\text { Fabricated } \\
\text { Kevlar composite) }\end{array}\end{array}$} & $\begin{array}{c}|c| \\
\text { Percentage of UTS } \\
\text { (Number of } \\
\text { Cycles) }\end{array}$ & $\begin{array}{c}70 \% \\
\text { (Number } \\
\text { of Cycles) }\end{array}$ & $\begin{array}{c}80 \% \\
\text { (Number of } \\
\text { Cycles) }\end{array}$ \\
\hline $0 \%$ of Graphene & 467529 & 202495 & 2631 \\
\hline $0.25 \%$ of Graphene & 515655 & 208649 & 3004 \\
\hline $0.75 \%$ of Graphene & 1000000 & 221527 & 3757 \\
\hline $1.25 \%$ of Graphene & 1000000 & 234678 & 4639 \\
\hline $1.75 \%$ of Graphene & 1000000 & 242649 & 5181 \\
\hline
\end{tabular}

The average number of cycles for three sets of samples of five different concentration of Graphene was inferred with respect to percentage of UTS, and tabulation above in Table 3.3. It is 
evident that the number of cycles with respect to percentage of UTS that the material can withstand before failure, increases with the addition/increase of Graphene percentage in the Kevlar composites. The Graphs for the for the Fatigue Tests, (Number of Cycles Vs Percentage of graphene) is plotted and $\mathrm{SN}$ curve is obtained.

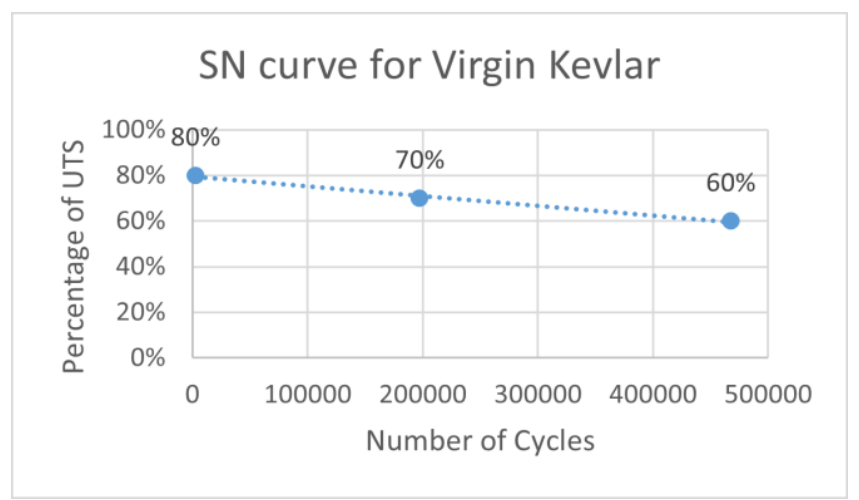

Fig. 3.10 SN curve for Virgin Kevlar Specimen

The number of fatigue cycles for the respective $60 \%, 70 \%, 80 \%$ of the UTS (MPa) is plotted in the above graph fig 3.10 from the Graph we infer that virgin Kevlar has comparatively less cycles than specimens with presence of Graphene.

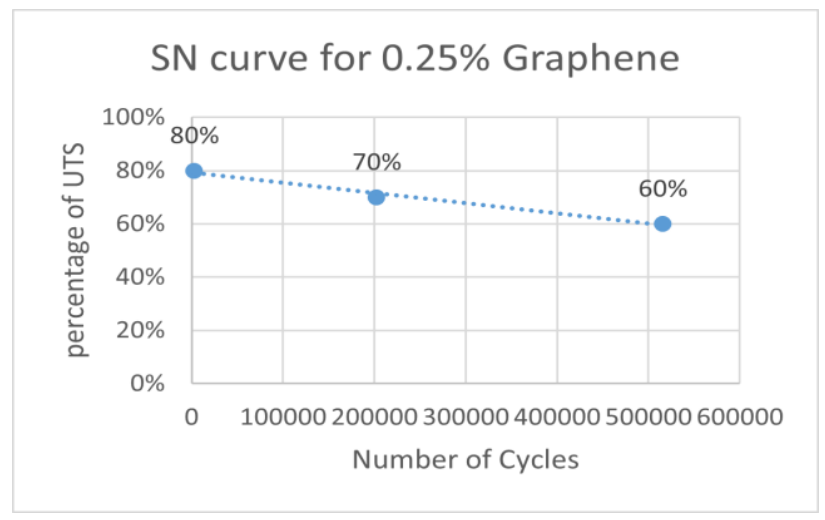

Fig. 3.11 SN curve for $0.25 \%$ Graphene Specimen

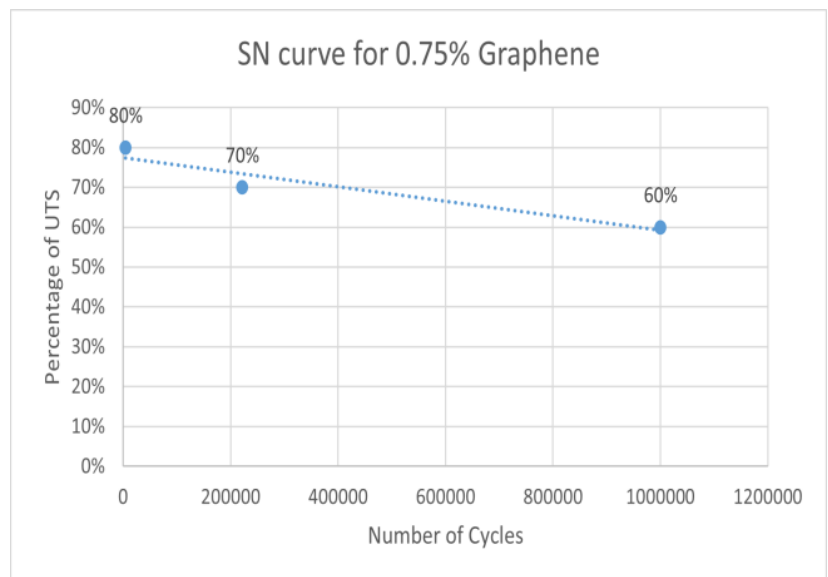

Fig. 3.12 SN curve for $0.75 \%$ Graphene Specimen
The number of fatigue cycles for the respective $60 \%, 70 \%, 80 \%$ of the UTS (MPa) is plotted in the above graph Fig. 3.12 from the Graph we infer that $0.75 \%$ graphene infused Kevlar specimen has increasing number of cycles and when tested with $60 \%$ of the UTS the specimen has reached an impressive $10^{6}$ cycles $(1,000,000$ cycle) without fracture and the SN curve is formed.

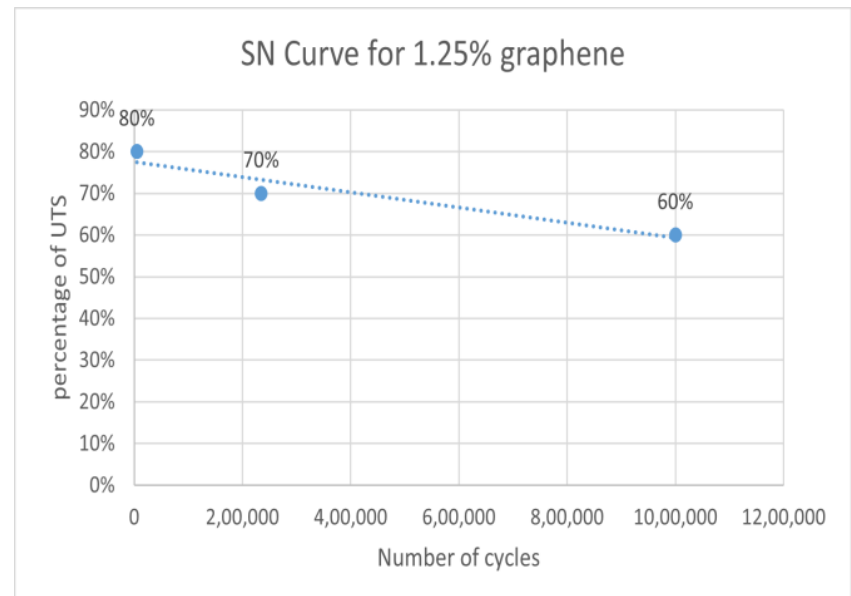

Fig. 3.13 SN curve for $1.25 \%$ Graphene panel

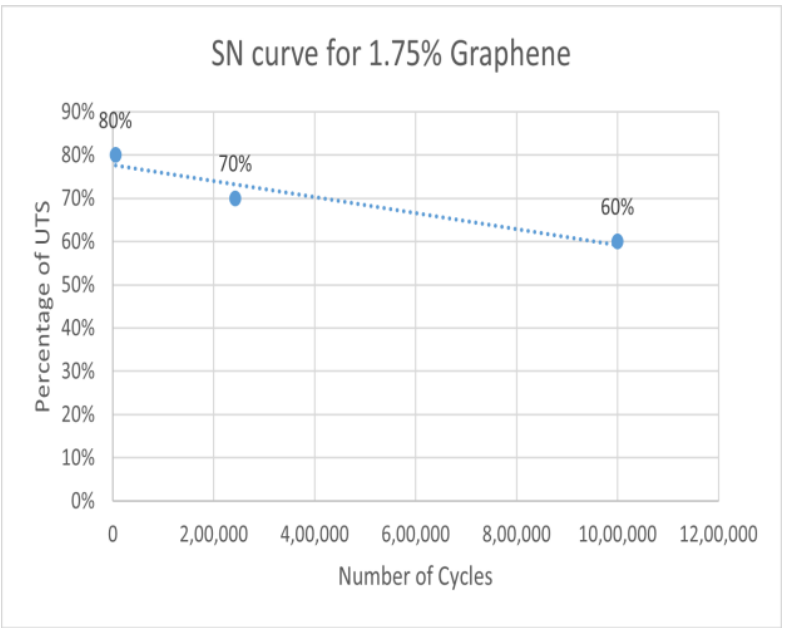

Fig. 3.14 SN curve for $1.75 \%$ Graphene panel

From Fig. 3.13 from the Graph, we infer that $1.25 \%$ graphene infused Kevlar specimen has increasing number of cycles and when tested with $60 \%$ of the UTS the specimen has reached $10^{6}$ cycles $(1,000,000$ cycle) without fracture and became a run out material.

From Fig. 3.14 from the Graph we infer that $1.75 \%$ graphene infused Kevlar specimen has increasing number of cycles and when tested with $60 \%$ of the UTS the specimen has reached a $10^{6}$ cycles $(1,000,000$ cycle) without fracture and became a run out material with the data of $60 \%, 70 \%$ and $80 \%$ we have a clear picture that $1.75 \%$ graphene has the Number of Cycles is higher for $1.75 \%$ of graphene when compared to other concentration. 


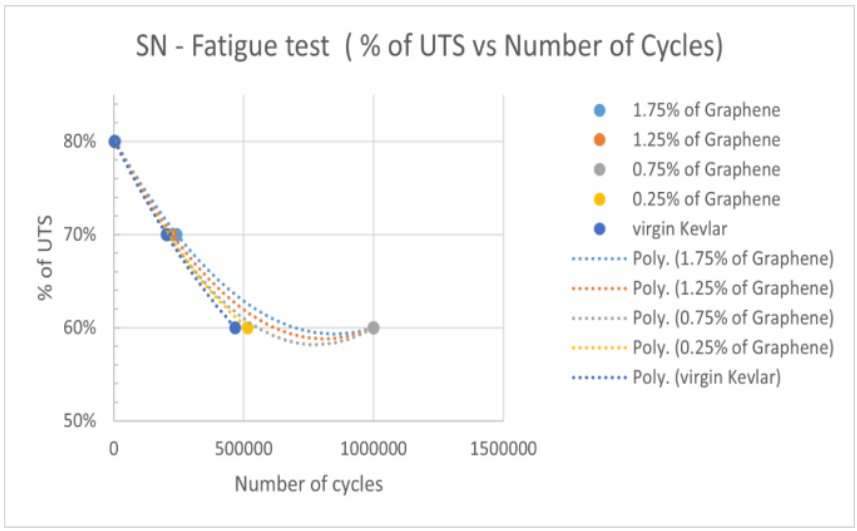

Fig. 3.15 Cumulative SN Curve (Fatigue Test)

We found that the Number of Cycles is higher for $1.75 \%$ of graphene - Kevlar Composite when compared to other concentration. There were significant improvements in the Time taken and the Axial load and the cycles that the specimen was able to withstand before failure, with the increase in Graphene concentration in the Kevlar composite panels. We allude to patterns of 100 to 10,000 as low cycle Fatigue (LCF), and more than 10,000 is alluded to as high cycle Fatigue (HCF), "This can be critical given that the specimen will have a huge number of cycles. VHCF strategies include a serious extremist to the fatigue testing. A definitive objective is to add very high cycle fatigue (VHCF) tests to the current LCF/HCF testing, which would make more precisely anticipate long haul weakness life of a specimen.

\section{CONCLUSION}

From the above results of Tensile and fatigue Testing and Raman spectroscopy analysis, comparing specimens of virgin and Graphene filled specimens, we could see a steady rise of increase in values of Tensile strengths and Fatigue life where there was a justified increase in values from specimen to specimen that is where virgin Kevlar specimen could withstand a max load of $35.653 \mathrm{KN}$ with an Ultimate Tensile Strength of $468.179\left(\mathrm{kN} / \mathrm{mm}^{\wedge} 2\right)$ and could withstand 467529, 202495, 2631 cycles with respect to the percentage of UTS of $60 \%, 70$ and $80 \%$ where specimen with $0.25 \%$ of graphene has comparative higher values where the specimen could withstand max load of $36.153 \mathrm{KN}$ with an Ultimate Tensile Strength of $486.846\left(\mathrm{kN} / \mathrm{mm}^{\wedge} 2\right)$ and could withstand 515655, 208649, 3004 cycles with respect to the percentage of UTS of $60 \%, 70$ and $80 \%$. On comparing the other Specimens of $0.75 \%$ graphene, $1.25 \%$ graphene, and $1.75 \%$ Graphene. The specimen with the Highest percentage of Graphene $(1.75 \%$ Graphene) proves to give the better output among the other four specimens.

where the specimen could withstand a max load of 40.798KN with an Ultimate Tensile Strength of 509.975 $\left(\mathrm{kN} / \mathrm{mm}^{\wedge} 2\right)$ and could stand $>1,000,000,242649,5181$ cycles with respect to the percentage of UTS of $60 \%, 70$, and $80 \%$. And has a greater spread of Graphene over the specimen making it more bonded and interlocked with the Kevlar matrix. Thus, the specimen with $1.75 \%$ of Graphene has more tensile strength and could stand very high cyclic loads. and from the study therefore from this experimental study, we infer that the addition of graphene nanoparticles gives rise to significant improvement in the mechanical behavior in particular fatigue behavior of the Kevlar composite.

During the onset of our work, we have faced many problems we have gone through every struggle and found an effective solution to overcome the issue, various phases and stages of the project made us understand the challenges that we face during designing, analyzing, fabrication and testing to make it a perfect project. The efforts that we have put in and the learning curve that we attained during this period of time made us learn a lot of things.

\section{ACKNOWLEDGEMENTS}

This experimental research was completely self-funded.

\section{REFERENCES}

[1] Kalantar J and Drzal LT. The bonding mechanism of aramid fibres to epoxy matrices. J Mater Sci 1990; $25: 4186-4202$

[2] JAM Ferreira1 et al. Fatigue behavior of Kevlar composites with nano clay-filled epoxy resin. Journal of Composite Materials 2012; 47:1885-1895.

[3] Oladapo Akinyede, Ram Mohan, AjitKelkar and Jag Sankar. Static and Fatigue Behavior of Epoxy/Fiberglass Composites Hybridized with Alumina Nano particles. Journal of Composite Materials 2009; 43(7): 769-781.

[4] Suhad D. Salman et al. Tension - Compression Fatigue behavior of plain woven kenaf/Kevlar hybrid composites. Bio-resources 2016; 11(2): 3575-3586.

[5] G. Fernando et al. Fatigue behavior of hybrid composites Part 1 Carbon/Kevlar hybrids. Journal of Materials Science 1988; 23: 3732-3743.

[6] Deepak M.V.S et al. Impact behavior of hybrid nano filled Kevlar reinforced composites. International research journal of engineering and technology 2020; 07: special issue

[7] S Manigandan et al. Experimental analysis of graphene nanocomposite on Kevlar. IOP Conference Series: Materials Science and Engineering 2017; 225(1): 012061 .

[8] Ismail, M. et al. A study on the low velocity impact response of hybrid Kenaf-Kevlar composite laminates through drop test rig technique. BioRes 2018; 13(2): 3045-3060. 92

[9] Lynn Penn, Fred Milanovich. Raman spectroscopy of Kevlar 49 fibre. Polymer 1979; 20(1): 31-36.

[10] J.M.Parente et al. Fatigue behavior of graphene composites: An overview. Procedia Structural Integrity 2020; 25: 282-293. 
International Journal of Applied Engineering Research ISSN 0973-4562 Volume 16, Number 7 (2021) pp. $590-597$

(C) Research India Publications. https://dx.doi.org/10.37622/IJAER/16.7.2021.590-597

[11] S Navid Hosseini Abbandanak et al. Effect of graphene on the interfacial and mechanical properties of hybrid glass/Kevlar fiber metal laminates. Journal of Industrial Textiles 2020.

[12] Zhenhua Ni, Yingying Wang, et al. Raman Spectroscopy and Imaging of Graphene. Nano Research 2008; 1: 273-291.

[13] Geim, A. K.; Novoselov, K. S. The rise of graphene. Nat. Mater. 2007; 6: 183-191.

[14] M. Zyskin et al. Simulation of the elastic properties of reinforced Kevlar-graphene composites. International Journal of Nanoscience 2012; 11(3).

[15] C. M. Manjunatha, N.Jagannathan, Et Al. The Fatigue and Fracture Behavior of Micron- Rubber And NanoSilica Particles Modified Epoxy Polymer. International Journal of Nanoscience 2012; 11(03): 1240002. 